\title{
Government regulations and stakeholders entrepreneurial orientation in achieving organiza- tional performance: An empirical study on private hospitals in Indonesia
}

\author{
Sandra Dewi ${ }^{{ }^{*}}$, Rhenald Kasalia, Tengku Ezni Balqiah ${ }^{\mathrm{a}}$ and Anton Wachidin Widjaja ${ }^{\mathrm{a}}$
}

${ }^{a}$ Faculty of Economics and Business, Universitas Indonesia, Depok 16424, Indonesia

\begin{tabular}{l}
${ }^{a}$ Faculty of Economics and Business, \\
\hline C H R O N I C L E \\
\hline Article history: \\
Received: July 28, 2018 \\
Received in revised format: Au- \\
gust 30, 2018 \\
Accepted: September 26, 2018 \\
Available online: \\
September 26, 2018 \\
\hline Keywords: \\
Entrepreneurial orientation \\
Government regulation \\
Stakeholder network capabil- \\
ity \\
Business model innovation \\
Hospital performance \\
\hline
\end{tabular}
A B S T R A C T

\begin{abstract}
The purpose of this study is to measure the impact of institutional environment as government regulation and managers' capabilities to maintain the relationship between the stakeholder networks and the entrepreneurial orientation within the context of the hospital industry in Indonesia. The results of data analysis from 105 small and medium private hospitals in the Jakarta city and surrounding areas show that the hospital entrepreneurial orientation was significantly influenced by government policies reflected by the legal certainty and bureaucratic attitudes that assist the implementation of the policies. Besides, it is proven that management capabilities to establish the relationships with many stakeholders, consisting of all existing partners and employees, also affect the growth of entrepreneurial orientation. Finally, the performance of the hospital is proven to be significantly influenced by the entrepreneurial orientation directly and also mediated by business model innovation. The results of this study become paradoxical because it is different from the opinion that the healthcare industry would not have accepted the concept of entrepreneurship.
\end{abstract}

C) 2018 by the authors; licensee Growing Science, Canada

\section{Introduction}

Entrepreneurial orientation is described as the extent to which the top level managers are inclined to take business-related risks, to encourage change and to embrace innovation to obtain a competitive advantage for their firms, and to compete aggressively with other firms (Douglas \& Ryman, 2003; Clauss, 2017). The firm's endeavor to win the competition is the primary focus in the field of strategic management (Teece et al., 1997), because it always tries to learn about the critical factors of the firms, as a determinant of performance. The firms need to know what elements and why the firm's performance can achieve superior success (Barringer \& Bluedorn, 1999; Madhok, 2002). One of the factors affecting the performance differences among firms is associated with the external environment of the organizations, received much attention from the researchers and the corporate practitioners (Venkatraman \& Presscott, 1990; Rosenbusch et al., 2013). It is said that the firm's ability to adapt and the level of sensitivity to its environment play a key role in determining the sustainability of corporate life (Chakravarthy, 1982). Nevertheless, from many empirical studies of external environmental mechanisms in influencing organizational performance, there is no conclusion of the final findings (Rosenbusch et al., 2013). This is because

* Corresponding author.

E-mail address: sandramochtar@yahoo.com (S. Dewi)

(C) 2018 by the authors; licensee Growing Science, Canada doi: $10.5267 /$ j.msl.2018.9.012 
the environmental impact on the level of organizational performance affects the specific behavior of companies that are strategic and will ultimately affect the firms' performance. The reactions of each firm are accurate, so they differ according to the characteristics, availability of resources and capabilities of the firms, as well as other contexts, in an attempt to persist in environmental uncertainty (Christensen \& Overdorf, 2000; Christensen \& Raynor, 2003; Christensen, 2009). Fundamentally, the traditional economics entrepreneurship is defined as the process that brings land, labor, and capital into combinations that make their value higher than before. Besides, the concept of entrepreneurial orientation has been used to measure the level of entrepreneurship in organizations (Hitt et al., 2001). Entrepreneurial orientation as a construct of academic study has its roots in the strategy making process, and it involves some set of policies and practices that guide entrepreneurial decisions and actions in an organization. Entrepreneurial orientation, as a central concept in the domain of entrepreneurship, has received a substantial amount of theoretical and empirical attention in recent years. The importance of entrepreneurial orientation among all the firms irrespective of sizes, ages, and industries is on the increase due to its massive influence on profitability and growth (Porter \& Teisberg, 2004; Porter \& Lee, 2013).

There have been different approaches to explore various types of firm's reactions to face the challenges of environmental uncertainty. Entrepreneurial strategy making process is a vital element for achieving firm success (Lumpkin \& Covin, 2011; Su et al., 2011; Miller, 1983a, 1983b). Implementation of this entrepreneurial strategy is said to be a strategic need of companies experiencing external environmental stress, due to its characteristics that drive the process of organizational change and adaptation (Kuratko, 2009; Kuratko et al., 2015; Nason et al., 2015). Therefore, the key success in this situation lies on the strategic behavior of the organization that comes from the corporate manager's mindset as a strategic decision maker. Proactive managers make changes, encourage innovation and recognize opportunities according to entrepreneurial thinking and demonstrating specific capabilities (Ireland et al., 2003; Dobrzykowski et al., 2015). Especially in an era of a shorten product life cycles, blurred inter-industry boundaries and increasingly transient competitive advantages, corporate managers are urged to make changes and innovate for the sustainability of the organization, based on their entrepreneurial mindset (Guo, 2006; Assink, 2006; Nikfarjam \& Zarifi, 2015).

The aim of this research is to deepen the understanding regarding the implementation of orientation of entrepreneurship in small and medium-sized hospital organizations in Indonesia, which are facing the impact of a transition of policy reform of hospital payment towards prospective payment system as part of the universal coverage program (Mboi, 2015; WHO, 2017). In the context of a strategic environment which demonstrates disruptive change, hospitals with an entrepreneurial orientation are believed to maintain their best performance through business model innovation and collaboration of strategic relationships between hospital management and the physician. The concept of entrepreneurial orientation used in this study is an aggregate or unidimensional construct from some studies (Miller 1983a, 2011; Covin \& Slevin, 1989, 1991). A firm cannot be categorized as an entrepreneurial firm only because it develops innovative technology or product lines, but imitates competitors while refusing to take any risks and not being proactive. Similarly, firms that make significant financial risks in investments to develop their products, but are not involved in product-market competition and innovation, cannot be categorized as behaving entrepreneurially (Covin, 1991).

\section{Theoretical Framework and Hypotheses}

Covin and Slevin (1991) presented a sophisticated model of entrepreneurial orientation. In this model, they described entrepreneurship as a firm-level behavior and asserted that not only individuals but also organizations behave entrepreneurially. Adoption of firm-behavior model has several advantages over traditional models based on individual traits of entrepreneurs. First, entrepreneurial effectiveness is a firm level phenomenon since it is a function of individual level and organizational level behavior. Next, behaviors and not personal characteristics give meaning to the entrepreneurial process. Firm-level behaviors can be reliable, verifiable and objectively measured. Finally, the firm level behavior is affected 
and therefore can be easily manipulated through the creation of organizational factors such as strategy, structure, culture and systems. Fig. 1 depicts the conceptual model of entrepreneurship as firm behavior developed by Covin and Slevin (1991).

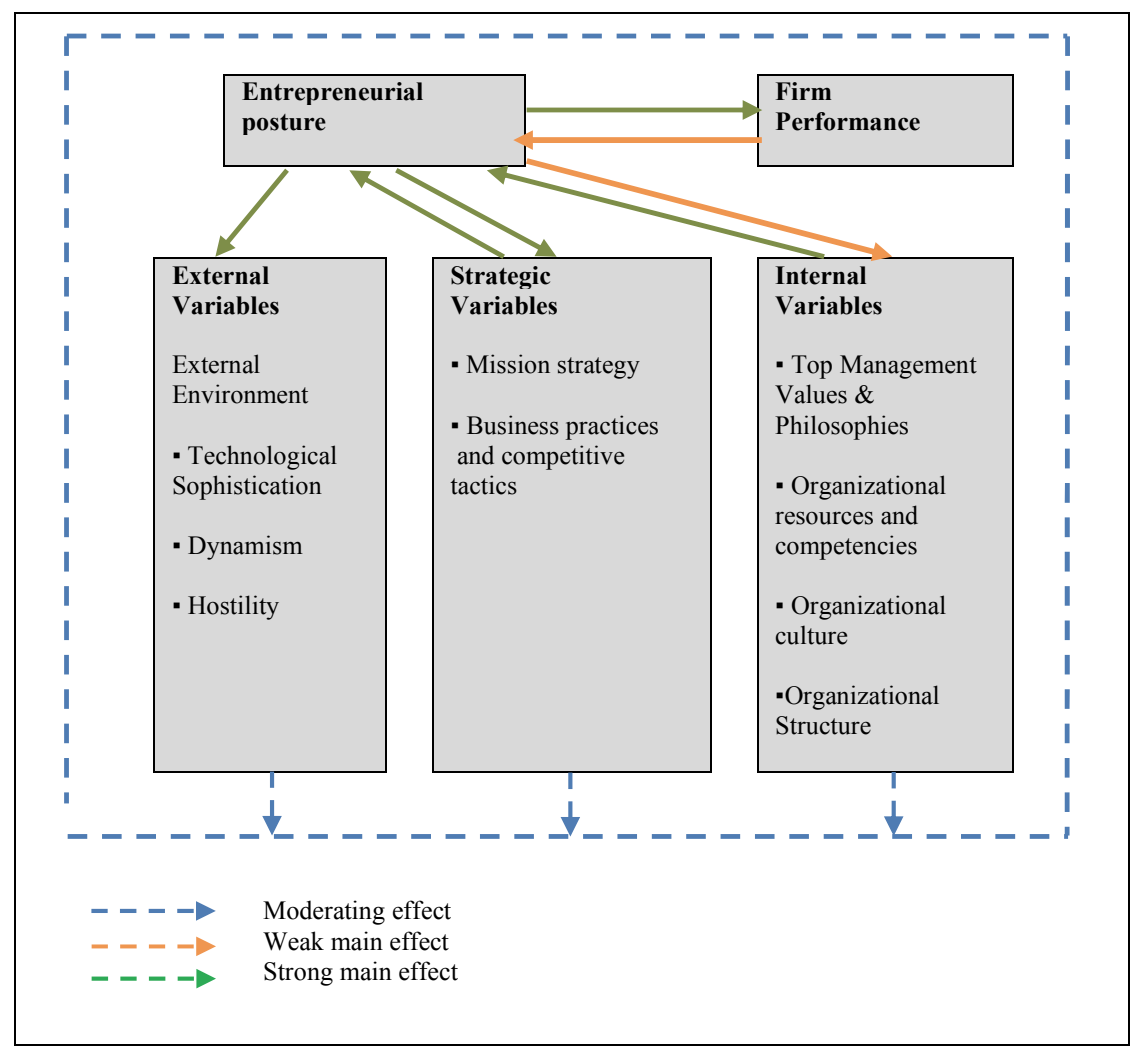

Fig. 1. A Conceptual Model of Entrepreneurship as Firm Behavior Source: Covin and Slevin (1991)

Lumpkin and Dess (1996) developed and expanded the previous models in several ways, especially adding two more dimensions to the construct of entrepreneurial orientation. As explained by them entrepreneurial orientation is referred to the processes, practices, and decision-making styles of organizations that act, entrepreneurially. The new dimensions introduced by them are 'autonomy' and 'competitive aggressiveness'. The developed model with those five elements (autonomy, innovativeness, risk taking, proactiveness, and competitive aggressiveness) are labelled today as multidimensional conceptualization as those five elements are believed to be independent and need not be co-varied.

Accordingly, high performance may be achieved even when only some of these dimensions are operating. As the same time, the impact of those individual factors on the firm performance may vary depending on the influence of contingent factors external to the organization (dynamism, munificence, complexity, industry characteristics) and internal factors to the organization (size, structure, strategy, strategy making process, firm resources, culture, top management team characteristics). Accordingly, notable assumptions of this model are 1) entrepreneurial orientation-performance relationship is context specific, 2) the dimensions of entrepreneurial orientation may vary independently of each other depending on the context; 3) it is primarily a firm-level phenomenon. The model developed by Lumpkin and Dess (1996) is illustrated in Fig. 2. 


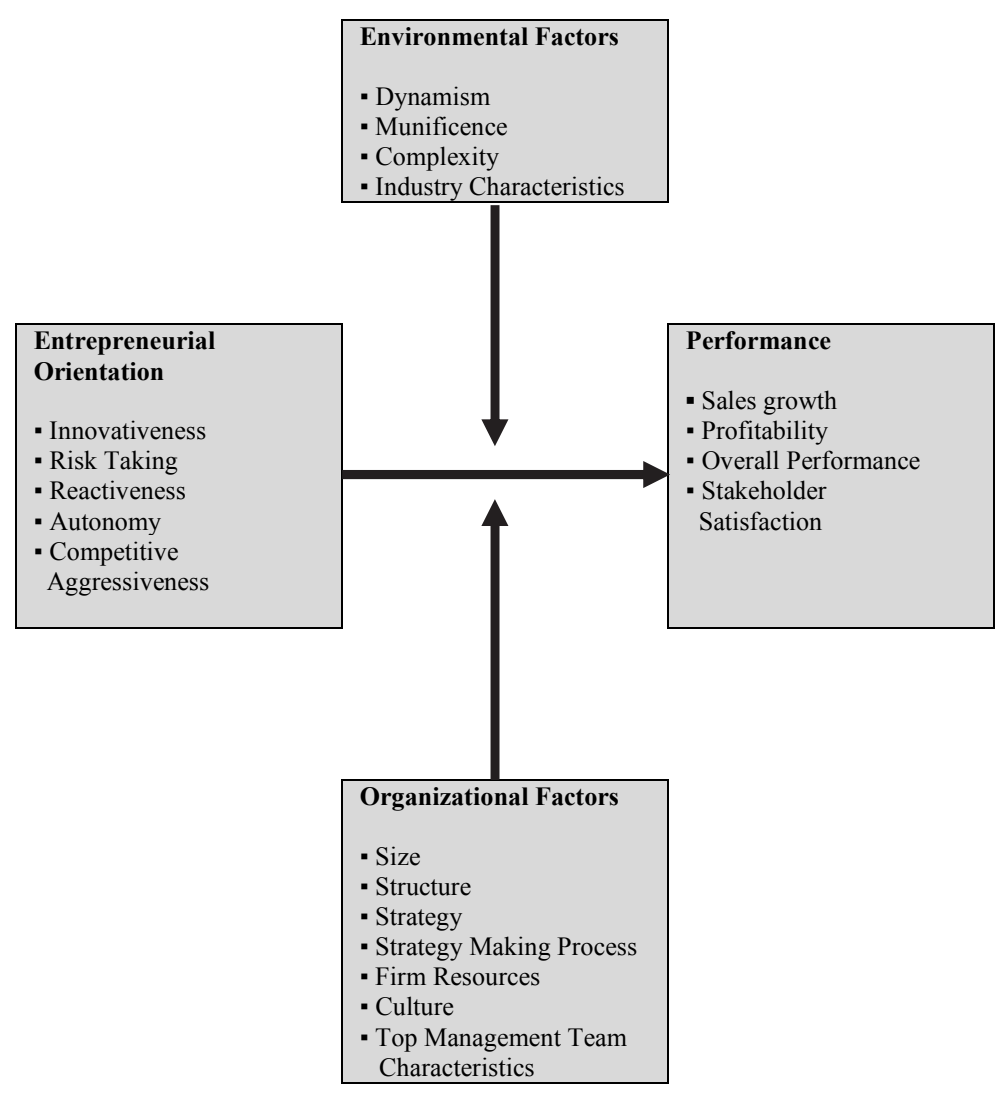

Fig. 2. Framework of Entrepreneurial Orientation Source: Lumpkin and Dess (1996)

On the other hand, it is said that entrepreneurial orientation is a strategic choice of organizational reaction aimed at enhancing corporate legitimacy in the eyes of stakeholders (Dickson \& Weaver, 2008; Schindehutte et al., 2008). Organizations will tend to be entrepreneurial if in general the regulation of the related industry sector, feels encouraging ease of entrepreneurial attitude, by forming an entrepreneurial environment (Gnyawali \& Fogel, 1994). Macro-level government regulations that promote entrepreneurship attitudes will be measured through the legal certainty dimension that illustrates (1) the clarity of the implementation of the legal system in the courts, (2) tax regulatory compliance (3) investment and financial security (4) regulation of new entrants and competition (5) the transparency of evaluation actions in the form of sanctions for those who violate regulations (Gnyawali \& Fogel, 1994). The existence of a macro regulation in a country that facilitates the establishment of an entrepreneurial climate is said to also increase the level of entrepreneurship orientation at the firm level (Dickson \& Weaver, 2008; Galahwali \& Fogel, 1994; Wales, 2013; Wales et al., 2016; Gómez-Haro et al. 2011).

The influence of micro-level government regulation on the level of entrepreneurship orientation of a firm in this research will be measured through dimensions of policy quality (Chadee \& Roxas, 2013). The aspects of the quality of the policy are reflected as (1) the smoothness and resistance assistance of the bureaucracy officers in the government offices faced by the firm in the management of their respective fields, (2) the compliance of the organization to run the regulation free of other charges or otherwise (Guhwali \& Fogel 1994) (3) the efficiency or inefficiency of time and cost of licensing arrangements include direct costs or time wastes due to intricate procedures, to the disruption of companies pursuing high productivity (Puffer et al., 2009). Hospitals will be more readily entrepreneurial oriented if supported by policies that support the business climate, administratively not complicated or straightforward to prevent the occurrence of cheating motives (Chadee \& Roxas, 2013). Also, it ensures the certainty of justice in the form of rewards for the run and the confidence of sanctions for violators (Dickson \& 
Weaver, 2008). With an efficient regulatory system, it means the government can provide a conducive business climate for entrepreneurial development, which can ensure the organization maintains its sustainability (Puffer et al., 2009; Hwang \& Christensen, 2008). Based on the above explanation, we can propose the following hypothesis:

Hypothesis 1: The government regulation has a positive influence on entrepreneurial orientation.

In this study, network capabilities is measured through 4 (four) dimensions including (1) coordination, (2) relational skills, (3) partner knowledge and (4) internal communication. Coordination is defined as coordinating activities among partner organizations. Relational skills are the ability to facilitate the exchange of mutually beneficial personalities. The ability to understand business partner includes the ability to obtain information in an organized and structured way about the partner. These three dimensions are linked to external organizations, which in this study include other organizations and suppliers. Internal communication is the ability of the organization to support the process of transferring the knowledge among parties within the organization and in this case among staff or workers including managers (Wales et al., 2013). Given the networking capabilities, inter-organizational relationships can be established within networks that can negotiate and persuade to gather more resources in the form of market information, ideas, problem-solving, social support, funding collaboration and other sources of financing from other parties in the network (Antoncic \& Hisrich, 2003).

Networking capabilities will be the firm's mechanism to proactively anticipate market opportunities, direct the use of resources more focused and targeted markets, and can encourage interaction in the introduction and education of innovative products or services. This condition will encourage a proactive, innovative and risk-taking behavior because, with the knowledge of suppliers or partners, the organization has enough information to guard the formation of cooperation to meet the interests of each party and resulting from the growth of transactions. It also benefits from the efficiency aspect because information on synergizing strategies and tactics will help managers make the best decisions to allocate resources, including better anticipation in long-term planning. Based on the above explanation, we can propose the following hypothesis:

Hypothesis 2: The stakeholder network capability has a positive influence on entrepreneurial orientation.

Associated with the dimension of entrepreneurial orientation that support change (innovative and proactive) as well as the tendency in decision making with measurable risk, entrepreneurial orientation is considered as a trigger of business model innovation (Bouncken et al., 2016). Entrepreneurial orientation affects business model innovation to prevent the status quo of the organization, which is due to inertia. This can occur because of the attitude of risk-taking, accept the existence of competition and proactive behavior by strengthening specific circumstances that are changing regarding the content, structure and governance of the organization's systems activities (Amit \& Schoemaker, 1993; Amit \& Zott, 2010). This explains that the selection of a firm's activities, and how it is implemented, showing the interaction between activities and the mechanism for the governance of operations are referred to the dynamics rules and can be changed rapidly by the firm's entrepreneurial orientation (Chesbrough, 2010; Amit \& Zott, 2010). By encouraging entrepreneurial orientation endogenously, a firm represented the experimental attitude and looked for potential new business models, before the pressures of external changes are forcing changes in the business model (Chesbrough, 2010). Based on the above explanation, we can propose the following hypothesis:

Hypothesis 3: The entrepreneurial orientation has a positive influence on business model innovation. 
The application of entrepreneurship orientation is no longer concerned by measuring its impact on deconstructing the dimensions of entrepreneurial orientation (proactive, innovative) and calculates risk taking but using the measurements of the outcomes shown in the form of the innovative business model. The entrepreneurial orientation influences business model innovation by preventing the occurrence of the organizational status quo, caused by inertia. This can happen because of risk-taking behavior, accepting competition and proactive organizational behavior by reinforcing specific unprecedented state changes in the organizational structure, organizational structure and governance (Zott \& Amitt, 2010). This means that the selection of a firm's activities with the routine way of execution, the interrelationship between events, and the mechanisms of management of operations referring to the dynamics of the rules that have long been applicable can be changed rapidly due to the entrepreneurial orientation factor (Chesbrough, 2010; Zott \& Amit, 2010). The entrepreneurial orientation will be reflected in an organization, which always encourages experiential attitudes endogenously and seeks new potential business models, before the pressure of external change that forces business model changes (Chesbrough, 2010).

In the context of current hospital conditions with digital disruption, entrepreneurship-oriented organizations will be more proactive in adopting the relatively new technology known in the industry. Thus, the innovation of the organization's business model will be further demonstrated by an Internet-based approach that will directly transform the entire value chain of the hospital's business process services business (Wade et al., 2018; Aral et al., 2013). The entrepreneurial orientation can affect the organization through a particular dimension of its business model builder and not simultaneously in all three aspects. Value creation, value proposition and value proposition entrepreneurial orientation can influence each by showing innovation separately or differing time of occurrence (Claus, 2015). Based on the above explanation, and we can propose the following hypothesis:

Hypothesis 4: The entrepreneurial orientation has a positive influence on business model innovation.

The relationship between the entrepreneurial orientations with firm performance is a significant concern to the researchers' history (Wales, 2016; George \& Marino, 2011). Many studies suggest an inconsistency in the relationship between entrepreneurial orientations on performance. Some reviews indicate direct links (Covin \& Slevin, 1989, 1991; Barney, 1991; Hinz \& Ingerfurth, 2013). Some researchers discovered the results of an indirect relationship between entrepreneurial orientations on performance (Wales et al., 2013). Even some studies indicate there has been an inconsistent relationship between entrepreneurial orientations on performance (Wales et al., 2013). It is assumed that companies with high entrepreneurial orientation tend to achieve better performance than companies that have the lower entrepreneurial orientation (Miller \& Friesen, 1982, 1983). However, there is another opinion that states that a high level of entrepreneurial orientation is not always, universally, directly provide added value compared to the conservative organization (Wales et al., 2013). In this study, the hospital with entrepreneurial characteristics is assumed to influence the achievement of better performance, because it has properties that enable proactive discover new opportunities earlier than the competition (Vandekerckhove \& Dentchev, 2005). Innovative attitude with proper risk calculation in hospitals tend to push the organization with improved performance, especially with the innovative business model, which can help open new markets (Claus, 2017). Based on the above explanation, we can propose the following hypothesis:

Hypothesis 5: The entrepreneurial orientation has a positive influence on organizational performance.

Based on the above explanation proposed research model is given in Fig. 3 as follows,

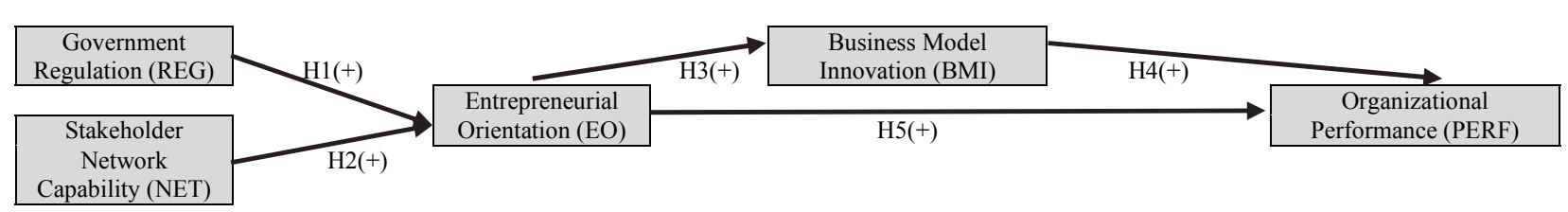

Fig. 3. Research Model

Table 1 summarizes the hypotheses of the survey. 
Table 1

Research Hypotheses

H1 The government regulation has a positive influence on entrepreneurial orientation.

H2 The stakeholder network capability has a positive influence on entrepreneurial orientation.

H3 The entrepreneurial orientation has a positive influence on business model innovation.

H4 The business model innovation has a positive influence on organizational performance.

H5 The entrepreneurial orientation has a positive influence on organizational performance.

\section{Research Method}

This research used the quantitative techniques implemented through data collection from the unit of analysis by using questionnaires. Before further research, the pre-test was accomplished to test the validity and reliability of each item indicator and the instrument as a whole. After the pretest stage was performed, the improvement of writing and the contents of the questionnaire was followed by the implementation of the survey according to the applicable protocol. After pretest, the obtained valid data came from 105 private hospitals. The analysis of the data collected from this study were processed by using SPSS and Structural Equation Model (SEM).

\section{Results}

After a measurement model of a valid and reliable research model was obtained, the next step was to perform a structural model analysis of the research model. This analysis was related to hypothesis testing. Overall model fit which was indicated by GOFI and significance test for latent variables correlation has indicated a good fit, which means the overall model fit of research model of this study was good. $(\mathrm{RMSEA}=0.07 ; \mathrm{NNFI}=0.96 ; \mathrm{CFI}=0.97 ; \mathrm{IFI}=0.97 ; \mathrm{Std} . \mathrm{RMR}=0.10 ; \mathrm{GFI}=0.92)$

Table 2

Research Hypotheses Test Results

\begin{tabular}{lcccc}
\hline Research Hypotheses & t-value* & Coefficient & Significant & Conclusion \\
\hline $\mathrm{H} 1: \mathrm{REG} \rightarrow(+)$ EO & 2.73 & 0.25 & Positive Significant & H1 supported \\
$\mathrm{H} 2: \mathrm{NET} \rightarrow(+)$ EO & 3.60 & 0.31 & Positive Significant & H2 supported \\
$\mathrm{H} 3: \mathrm{EO} \rightarrow(+)$ BMI & 8.30 & 0.63 & Positive Significant & H3 supported \\
$\mathrm{H} 4 ; \mathrm{BMI} \rightarrow(+)$ PERF & 5.05 & 0.49 & Positive Significant & H4 supported \\
H5: EO $\rightarrow(+)$ PERF & 3.58 & 0.74 & Positive Significant & H5 supported \\
\hline *
\end{tabular}

From the significance test from Table 2, it can be seen that the correlations between all latent variables were found to be the significant positive. The results also indicate that the five hypotheses can be accepted.

\section{Discussion}

This study aimed to provide an insight into the influence of the perceived regulatory environment on the exhibition of entrepreneurial orientation. The implementation of entrepreneurship orientation in the organization will play an essential role in maintaining the existence and winning the competition in the hospital industry environment of Indonesia. The results of this research with data from 105 private hospitals in Indonesia have proven that the government regulation significantly influenced the entrepreneurial climate that supports the growth of hospital industry. The stakeholder network capability also has maintained a significant positive impact and will encourage the entrepreneurial orientation in hospital organizations. The entrepreneurial orientation influences business model innovation by preventing the occurrence of the organizational status quo, caused by inertia (Zott \& Amitt, 2010). Barriers to long- 
standing operations are referred to as resource rigidity and routine rigidity (Gilbert, 2005). Entrepreneurial orientation positively affects the improvement of organizational performance, either directly or through business model innovation. Business model innovation proves to be an outcome of entrepreneurial implementation, so that different types of business model innovation between hospitals can be found based on the differences of the kind of innovation per sub dimension which depends on the choice of each hospital.

\section{Conclusion}

This research has concluded that the hospital entrepreneurial orientation (EO) was significantly influenced by government policies reflected by the legal certainty and bureaucratic attitudes that assist the implementation of policies. Besides, it has been proven that management capabilities to establish relationships with many stakeholders, consisting of all existing partners and employees, also affect the growth of entrepreneurial orientation. Finally, the performance of the hospital was proven to be significantly influenced by the entrepreneurial orientation directly and also mediated by business model innovation. The contributions of this study stem from the development of a model which examines the antecedent influence that crucial factors from the regulatory pillar of the institutional environment may have upon the manifestation of EO among Indonesia private hospitals. A primary implication to the broader generalized EO literature is that institutional factors can help explain the strength of EO manifested by an organization. This research emphasizes the need for emerging economies to take into account institutional considerations when encouraging the emergence of entrepreneurial orientation among their companies. Thus, a second implication is that the results of this study may be useful for governmental practitioners, as it demonstrates the potentially marginal impact of their decisions concerning critical institutions, and highlights the importance of establishing governmental relationships with SMEs within developing economic contexts to foster the manifestation of their entrepreneurial. The study provides some insight and understanding for practitioners and all hospital industry stakeholders to achieve performance growth and organizational sustainability by deepening the knowledge of hospital business model innovation and collaboration of strategic relational assets in the form of collaborative relationship of the hospital with physician profession.

\section{Acknowledgements}

The author wishes to thank the Chairman of Indonesian Hospital Association (PERSI) (Dr. Kuntjoro A.P, MARS and all staffs), and the research team member: Dr. Ristina Basri, MARS, Dr. Sitti Baidoeri, MARS, Dr. Peter B, MARS, Nadya P. Suryaputri, SIA and Rachma Rasjid, SE, for their support and valuable suggestions on the completion of this study.

\section{References}

Al-Amin, M., Weech-Maldonado, R., \& Pradhan, R. (2014). Hospital-Physician Relationships: Implications from The Professional Service Firms Literature. In Annual Review of Health Care Management: Revisiting The Evolution of Health Systems Organization, 15, 165-184.

Amit, R., \& Zott, C. (2010) Business model innovation: Creating value in times of change. Working paper-IESE Business Scholl, University of Navara, 1-15

Amit, R., \& Schoemaker, P. J. H. (1993) Strategic assets and organisational rent. Strategic Management Journal, 14, 33-46

Antoncic, B., \& Hisrich, R. D. (2003). Clarifying the intrapreneurship concept. Journal of Small Business and Enterprise Development, 10(1), 7-24.

Assink, M. (2006). Inhibitors of disruptive innovation capability: a conceptual model. European Journal of Innovation Management, 9(2), 215-233.

Barney, J. B. (1991). Firm resources and sustained competitive advantage. Journal of Management, 17(1), 99-120 
Barringer, B. R., \& Bluedorn, A. C. (1999). The relationship between corporate entrepreneurship and strategic management. Strategic Management Journal, 20(5), 421-444.

Bouncken, R. B., Lehmann, C., \& Fellnhofer, K. (2016). The role of entrepreneurial orientation and modularity for business model innovation in service companies. International Journal of Entrepreneurial Venturing, 8(3), 237-260.

Chadee, D., \& Roxas, B. (2013). Institutional environment, innovation capacity and firm performance in Russia. Critical Perspectives on International Business, 9(1/2), 19-39.

Chakravarthy, B. S. (1982). Adaptation: A promising metaphor for strategic management. Academy of Management Review, 7(1), 35-44.

Chesbrough, H. (2010). Business model innovation: opportunities and barriers. Long Range Planning, 43(2-3), 354-363.

Christensen, C. M., \& Overdorf, M. (2000). Meeting the challenge of disruptive change. Harvard Business Review, 78(2), 66-77.

Christensen, C. M., Grossman, J. H., \& Hwang, J. (2009). The innovator's prescription: A disruptive solution for health care, New York: McGraw-Hill.

Christensen, C.M. \& Raynor, M (2003). The innovator's solution: Creating and sustaining successful growth. Boston, MA: Harvard Business School Press.

Christensen, C. M., Raynor, M. E., \& McDonald, R. (2015). What is disruptive innovation. Harvard Business Review, 93(12), 44-53.

Clauss, T. (2017). Measuring business model innovation: conceptualization, scale development, and proof of performance. $R \& D$ Management, 47(3), 385-403.

Covin, J. G. (1991). Entrepreneurial versus conservative firms: A comparison of strategies and performance. Journal of Management Studies, 28(5), 439-462.

Covin, J. G., \& Lumpkin, G. T. (2011). Entrepreneurial orientation theory and research: Reflections on a needed construct. Entrepreneurship Theory and Practice, 35(5), 855-872.

Covin, J. G., \& Slevin, D. P. (1989). Strategic management of small firms in hostile and benign environments. Strategic management journal, 10(1), 75-87.

Covin, J. G., \& Slevin, D. P. (1991). A conceptual model of entrepreneurship as firm behavior. Entrepreneurship Theory and Practice, 16(1), 7-26.

Dickson, P. H., \& Weaver, K. M. (2008). The role of the institutional environment in determining firm orientations towards entrepreneurial behavior. International Entrepreneurship and Management Journal, 4(4), 467-483.

Dobrzykowski, D. D., Callaway, S. K., \& Vonderembse, M. A. (2015). Examining pathways from innovation orientation to patient satisfaction: A relational view of healthcare delivery. Decision Sciences, 46(5), 863-899.

Douglas, T. J., \& Ryman, J. A. (2003). Understanding competitive advantage in the general hospital industry: Evaluating strategic competencies. Strategic Management Journal, 24(4), 333-347.

George, B. A., \& Marino, L. (2011). The epistemology of entrepreneurial orientation: Conceptual formation, modeling, and operationalization. Entrepreneurship Theory and Practice, 35(5), 989-1024.

Gómez-Haro, S., Aragón-Correa, J. A., \& Cordón-Pozo, E. (2011). Differentiating the effects of the institutional environment on corporate entrepreneurship. Management Decision, 49(10), 1677-1693.

Guo, K.L. (2006) Entrepreneurial management in health services: An integrative model. Journal of Health and Human Services Administration, 28 (3/4), 504-531.

Gnyawali, D. R., \& Fogel, D. S. (1994). Environments for entrepreneurship development: key dimensions and research implications. Entrepreneurship Theory and Practice, 18(4), 43-62.

Hair, J. F., Black, W. C., Babin, B. J., \& Anderson, R. E., \& Tatham, R. L. (2006) Multivariate data analysis. (Vol. 6). Upper Saddle River, NY: Pearson Prentice Hall.

Hinz, V., \& Ingerfurth, S. (2013). Does ownership matter under challenging conditions?: On the relationship between organizational entrepreneurship and performance in the healthcare sector. Public Management Review, 15(7), 969-991.

Hitt, M. A., Ireland, R. D., Camp, S. M., \& Sexton, D. L. (2001). Strategic entrepreneurship: Entrepreneurial strategies for wealth creation. Strategic management journal, 22(6-7), 479-491. 
Hwang, J., \& Christensen, C. M. (2008). Disruptive innovation in health care delivery: a framework for business-model innovation. Health Affairs, 27(5), 1329-1335.

Ireland, R.D., Kuratko, D. F., \& Covin, J. G (2003) Antecedents, elements and consequences of corporate entrepreneurship strategy. Academy of Management Best Conference Paper, L1 - L6.

Kuratko, D. F. (2009). The entrepreneurial imperative of the 21 st century. Business Horizons, 52(5), 421428.

Kuratko, D. F., Hornsby, J. S., \& Hayton, J. (2015). Corporate entrepreneurship: the innovative challenge for a new global economic reality. Small Business Economics, 45(2), 245-253.

Madhok, A. (2002). Reassessing the fundamentals and beyond: Ronald Coase, the transaction cost and resource-based theories of the firm and the institutional structure of production. Strategic Management Journal, 23(6), 535-550.

Miller, D. (1983a) revisited: A reflection on EO research and some suggestions for the future. Entrepreneurship Theory and Practice, 35(5), 873-894.

Miller, D. (1983b). The correlates of entrepreneurship in three types of firms. Management science, 29(7), 770-791.

Miller, D., \& Friesen, P. H. (1982). Innovation in conservative and entrepreneurial firms: Two models of strategic momentum. Strategic management journal, 3(1), 1-25.

Miller, D., \& Friesen, P. H. (1983). Strategy-making and environment: the third link. Strategic management journal, 4(3), 221-235.

Mboi, N. (2015). Indonesia: on the way to universal health care. Health Systems \& Reform, 1(2), 91-97.

Nason, R. S., McKelvie, A., \& Lumpkin, G. T. (2015). The role of organizational size in the heterogeneous nature of corporate entrepreneurship. Small Business Economics, 45(2), 279-304.

Nikfarjam, A., \& Zarifi, S. (2015). Exploring the effects of entrepreneurial marketing factors on SMEs. Uncertain Supply Chain Management, 3(4), 333-338.

Porter, M. E., \& Teisberg, E.O. (2004) Redefining competition in health care. Harvard Business Review, June, 65-76.

Porter, M. E., \& Lee, T. H. (2013). The strategy that will fix healthcare. Harvard Business Review, October, 1-19.

Rosenbusch, N., Rauch, A., \& Bausch, A. (2013). The mediating role of entrepreneurial orientation in the task environment-performance relationship: A meta-analysis. Journal of Management, 39(3), 633-659.

Schindehutte, M., Morris, M. H., \& Kocak, A. (2008). Understanding market-driving behavior: the role of entrepreneurship. Journal of Small Business Management, 46(1), 4-26.

$\mathrm{Su}, \mathrm{Z}$., Xie, E., Wang, D., \& Li, Y. (2011). Entrepreneurial strategy making, resources, and firm performance: evidence from China. Small Business Economics, 36(2), 235-247.

Teece, D. J., Pisano, G., \& Shuen, A. (1997). Dynamic capabilities and strategic management. Strategic management journal, 18(7), 509-533.

Vandekerckhove, W., \& Dentchev, N. A. (2005). A network perspective on stakeholder management: Facilitating entrepreneurs in the discovery of opportunities. Journal of Business Ethics, 60(3), 221232.

Venkatraman, N., \& Prescott, J. E. (1990). Environment-strategy coalignment: An empirical test of its performance implications. Strategic Management Journal, 11(1), 1-23.

Wales, W. J. (2016). Entrepreneurial orientation: A review and synthesis of promising research directions. International Small Business Journal, 34(1), 3-15.

Wales, W. J., Patel, P. C., Parida, V., \& Kreiser, P. M. (2013). Nonlinear effects of entrepreneurial orientation on small firm performance: the moderating role of resource orchestration capabilities. Strategic Entrepreneurship Journal, 7(2), 93-121.

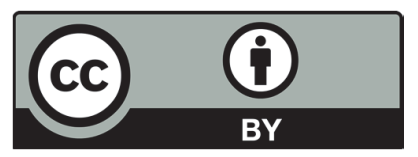

(C) 2018 by the authors; licensee Growing Science, Canada. This is an open access article distributed under the terms and conditions of the Creative Commons Attribution (CCBY) license (http://creativecommons.org/licenses/by/4.0/). 